OPEN ACCESS

Edited by:

Anna Kramvis,

University of the Witwatersrand, Johannesburg, South Africa

Reviewed by:

Michael Bouchard,

Drexel University, United States

Kohji Moriishi,

University of Yamanashi, Japan

${ }^{*}$ Correspondence:

Min Chen

mchen@hospital.cqmu.edu.cn

Specialty section:

This article was submitted to

Virology,

a section of the journal

Frontiers in Microbiology

Received: 02 December 2020

Accepted: 18 February 2021

Published: 11 March 2021

Citation:

Zhang J, Ling N, Lei Y, Peng M, Hu P and Chen M (2021) Multifaceted Interaction Between Hepatitis B Virus Infection and Lipid Metabolism

in Hepatocytes: A Potential Target of Antiviral Therapy for Chronic

Hepatitis $B$

Front. Microbiol. 12:636897. doi: 10.3389/fmicb.2021.636897

\section{Multifaceted Interaction Between Hepatitis B Virus Infection and Lipid Metabolism in Hepatocytes: A Potential Target of Antiviral Therapy for Chronic Hepatitis B}

\author{
Jiaxuan Zhang, Ning Ling, Yu Lei, Mingli Peng, Peng Hu and Min Chen* \\ Key Laboratory of Molecular Biology for Infectious Diseases, Ministry of Education, Department of Infectious Diseases, \\ Institute for Viral Hepatitis, The Second Affiliated Hospital of Chongqing Medical University, Chongqing, China
}

Hepatitis B virus (HBV) is considered a "metabolic virus" and affects many hepatic metabolic pathways. However, how HBV affects lipid metabolism in hepatocytes remains uncertain yet. Accumulating clinical studies suggested that compared to nonHBV-infected controls, chronic HBV infection was associated with lower levels of serum total cholesterol and triglycerides and a lower prevalence of hepatic steatosis. In patients with chronic HBV infection, high ALT level, high body mass index, male gender, or old age was found to be positively correlated with hepatic steatosis. Furthermore, mechanisms of how HBV infection affected hepatic lipid metabolism had also been explored in a number of studies based on cell lines and mouse models. These results demonstrated that HBV replication or expression induced extensive and diverse changes in hepatic lipid metabolism, by not only activating expression of some critical lipogenesis and cholesterolgenesis-related proteins but also upregulating fatty acid oxidation and bile acid synthesis. Moreover, increasing studies found some potential targets to inhibit HBV replication or expression by decreasing or enhancing certain lipid metabolism-related proteins or metabolites. Therefore, in this article, we comprehensively reviewed these publications and revealed the connections between clinical observations and experimental findings to better understand the interaction between hepatic lipid metabolism and HBV infection. However, the available data are far from conclusive, and there is still a long way to go before clarifying the complex interaction between HBV infection and hepatic lipid metabolism.

Keywords: hepatitis B virus, chronic hepatitis B, lipid metabolism, apolipoprotein, hepatic steatosis, metabolic signaling pathway, nuclear factors

\section{INTRODUCTION}

Hepatitis B virus (HBV), a member of the Hepadnaviridae family, is one of the smallest enveloped animal DNA viruses and the pathogen to cause Hepatitis B. Although HBV vaccines and effective antiviral drugs have been available for more than 20 years, chronic HBV infection (CHB) remains a global public health problem, especially in Asia (Megahed et al., 2020). Increasing 
attention has been paid to the relationship between $\mathrm{HBV}$ infection and hepatic lipid metabolism recently. Several large-scale clinical studies have been conducted to explore the correlation of hepatic steatosis with $\mathrm{CHB}$. Meanwhile, accumulated data have shown that $\mathrm{HBV}$ replication and expression could interact with some lipid metabolism-related transcription factors (TFs) and nuclear receptors (NRs) (BarYishay et al., 2011; Wagner et al., 2011), including retinoid X receptor $\alpha(\mathrm{RXR} \alpha)($ Reese et al., 2011), farnesoid X Receptor (FXR) (Mouzannar et al., 2019), estrogen-related receptors (ERs) (Wang et al., 2012), or peroxisome proliferator-activated receptors (PPARs) (Jiang et al., 2019). Simultaneously, cellular or animal studies have unveiled some mechanisms of how HBV affected the activity or expression of multiple factors involved in hepatic lipid metabolism, or vice versa (Lin et al., 2015; Wang C.C. et al., 2015; Shi et al., 2016; Suliman et al., 2019). Therefore, based on these recent clinical and basic studies, this article comprehensively reviewed the latest progress and opinions regarding $\mathrm{HBV}$ infection and hepatic lipid metabolism, and provided new insight into approaches for treating $\mathrm{CHB}$.

\section{THE RISK OF HEPATIC STEATOSIS IN PATIENTS WITH CHRONIC HBV INFECTION}

Hepatic steatosis, also known as fatty liver disease, includes alcohol-related fatty liver disease (AFLD) and non-alcoholic fatty liver disease (NAFLD). So far, the prevalence of NAFLD in CHB patients remains unconfirmed. A meta-analysis conducted in Machado et al. (2011) showed that in CHB patients, the overall hepatic steatosis prevalence was $29.6 \%$, which was lower than that in hepatitis C virus (HCV)-infected patients. Subsequently, one large-scale cross-sectional retrospective study involving 33,439 subjects in health checkup (Cheng et al., 2013) showed that the prevalence of fatty liver was lower in hepatitis B surface antigen positive $\left(\mathrm{HBsAg}^{+}\right)$populations $(38.9 \%)$ than in the $\mathrm{HBsAg}^{-}$ group (44.5\%), and HBsAg positivity was inversely correlated with fatty liver. These results were consistent with another largesample prospective cohort study (Joo et al., 2017), which showed that HBsAg seropositivity was associated with a lower risk of developing NAFLD during an approximately 10-year followup of 83,339 non-NAFLD Korean adults with normal alanine aminotransferase (ALT) levels at baseline. Besides, a hospitalbased case-control retrospective study showed that the negative correlation between $\mathrm{HBV}$ infection and fatty liver appeared only in patients with new-onset CHB (Zhong et al., 2018). In addition, these clinical studies had found that serum level of total cholesterol, triglycerides, HDL-C, or LDL-C in CHB patients was lower than that of non-HBV-infected controls (Wong et al., 2012; Cheng et al., 2013; Joo et al., 2017). A study involving only female subjects in health checkup reported that the prevalence of fatty liver exhibited no significant difference between $\mathrm{HBV}$-infected patients and $\mathrm{HBV}$-free subjects (Wang et al., 2019).
Apart from the comparison of the prevalence of hepatic steatosis between $\mathrm{CHB}$ patients and non-CHB controls, factors involved in NAFLD development among $\mathrm{CHB}$ populations were thoroughly investigated in some studies. Factors that had positive or negative influence on hepatic steatosis in $\mathrm{CHB}$ patients were shown in Supplementary Table 1. Among these factors, high BMI, male gender, old age, and high ALT levels were commonly reported to be positively associated with NAFLD in CHB patients (Peng et al., 2008; Shi et al., 2008; Zheng et al., 2010; Machado et al., 2011; Wong et al., 2012; Cheng et al., 2013; Wang et al., 2014, 2019; Enomoto et al., 2016; Charatcharoenwitthaya et al., 2017; Joo et al., 2017; Chen et al., 2018; Hui et al., 2018; Zhong et al., 2018; Zhu et al., 2019). However, there was no evident correlation between hepatic steatosis and HBeAg status or HBV DNA levels (Peng et al., 2008; Charatcharoenwitthaya et al., 2017).

Nevertheless, these clinical studies suggested that HBsAg positivity might be related to NAFLD's low occurrence, while the status of liver inflammation and clinical or metabolic factors during disease progress would influence this relationship. Furthermore, differences in clinical study design, sample size, method for hepatic steatosis detection, or statistical method would deduce different conclusions. Clarifying the relationship between HBV infection and NAFLD development will require additional multi-center, large-sample, case-controlled clinical studies with hepatic steatosis assessment in liver biopsy samples.

\section{HBV-INDUCED CHANGES IN FATTY ACID METABOLISM}

Fatty acid metabolism in the liver is controlled by a complex network of TFs and proteins (Alves-Bezerra and Cohen, 2017). In different cellular or mouse models, HBV replication or expression increased lipid biosynthesis-related factor sterol regulatory element-binding protein 1c (SREBP1c). SREBP1c activation upregulates the expression of lipogenic enzymes, such as fatty acid synthase (FAS), stearoyl-CoA desaturase (SCD), and acetyl-CoA carboxylase (ACC), and thus fatty acid synthesis (Wang Y. et al., 2015; Alves-Bezerra and Cohen, 2017). By the proteomic analysis of liver tissue from HBV transgenic mice, Yang et al. (2008) found that the expression of fatty acid-binding protein 5 (FABP5) and acetyl-CoA binding protein (ACBP), which were involved in fatty acid metabolism and synthesis, was significantly up-regulated compared to that in wild-type mice.

Levels of various types of lipids were also examined by mass spectrometry in different stages of chronic HBV infection. Arain et al. (2018) found that HBV patients showed significantly higher levels of serum saturated fatty acids (SFAs) or monounsaturated fatty acids (MUFAs) (myristic acid or palmitic acid), and lower levels of polyunsaturated fatty acids (PUFAs) (linoleic acid, eicosatrienoic acid, etc.). Moreover, a higher level of urine palmitic acid, stearic acid, oleic acid, or cholesterol was shown in CHB patients than in the control group (Dittharot et al., 2018), and a large difference between urine and serum metabolite 
profiles was found in the same CHB subject (Yang et al., 2016). In an AdHBV-infected primary rat hepatocyte model, metabolomic and transcriptomic datasets synergistically showed a noticeable increase in the long-chain FFA pool (Lamontagne et al., 2018). Furthermore, in a stable HBV-producing cell line HepG2.2.15, Li et al. (2015) found that the total fatty acid content was increased, but the essential fatty acids $\alpha$-linolenic acid and linoleic acid were decreased.

Apart from reports that HBV increased lipogenesis, several other studies showed that HBV infection also increased fatty acid oxidation and reduced lipid droplets (LD) formation. Yasumoto et al. (2017) showed that the content of intracellular TGs and the average size of a single LD were significantly reduced in HBV-infected or transfected cells compared to control cells, and that was because of decreased levels of proteins involved in LD expansionary and lipid storage. Studies also showed that HBV replication increased adiponectin expression (a downstream gene of PPAR $\gamma$ ) (Yoon et al., 2011). Adiponectin alleviated lipid accumulation by increasing carnitine palmitoyltransferase 1 (CPT1) activity, enhancing hepatic fatty acid oxidation, and reducing ACC and FAS activity (Wang M.D. et al., 2016; Fang and Judd, 2018).

Overall, these results from experimental studies indicated that HBV infection not only enhanced fatty acid synthesis and lipogenesis, but also increased fatty acid oxidation and lipolysis.

\section{CHANGES IN PHOSPHOLIPIDS METABOLISM DURING HBV INFECTION}

In addition, significant changes in phospholipids and sphingolipids were found in $\mathrm{HBV}$ expressed primary hepatocytes or cell lines and CHB patients. Li et al. (2015) found that $\mathrm{HBV}$ infection activated the expression of choline kinase alpha to upregulate phosphatidylcholine biosynthesis. Huang et al. (2019) found that serum phosphatidylcholine, phosphatidylethanolamine, and lysophosphatidic acid were increased in $\mathrm{HBsAg}^{+}$patients compared to $\mathrm{HBsAg}^{-}$individuals. This study also found that phosphatidylcholine synthesis-related enzymes, phosphoethanolamine transferase A and phospholipid phosphatase 1 (LPP1), were upregulated after HBV infection. Different pattern of phospholipid changes was displayed in different stages of chronic HBV infection. Schoeman et al. (2016) found that decreased phospholipids, lysophospholipids, and sphingomyelin in the immune tolerance phase of HBV infection compared to healthy controls. Also, Qu et al. (2014) found that serum sphingolipids in $\mathrm{CHB}$ patients were significantly higher than those in healthy controls, especially in patients with $\mathrm{HBV}$-associated acute-on-chronic liver failure (HBV-ACLF), suggesting that serum sphingolipid levels might be associated with $\mathrm{HBV}$ infection and disease progression.

\section{HBV-INDUCED CHANGES IN CHOLESTEROL METABOLISM}

Changes in cholesterol metabolism were evidenced during HBV infection. Li et al. (2013) found in HepG2 cells that $\mathrm{HBV}$ replication increased the expression of LDLR and hydroxymethylglutaryl coenzyme A reductase (HMGCR), leading to an increase in cholesterol intake and synthesis. Wang et al. (2018) showed that in a mouse model with alcoholic fatty liver, HBV replication increased hepatic cholesterol deposition by enhancing the expression of the cholesterol synthesis-related genes SREBP2 and HMGCR. Rodgers et al. (2009) found a high level of 7-dehydrocholesterol (7-DHC) in hepatocytes with $\mathrm{HBV}$ replication. 7-DHC is the direct precursor of free cholesterol and the substrate of 7-dehydrocholesterol reductase (DHCR7). Xiao et al. (2020) found significantly increased DHCR7 expression in livers of hepatocellular carcinoma (HCC) patients with $\mathrm{HBV}$ infection. 7-DHC was also a biosynthesis precursor to vitamin $\mathrm{D}$, thus increased DHCR7 promoted cholesterol synthesis while inhibited Vitamin D production (Prabhu et al., 2016). Therefore, vitamin D was frequently found to be insufficient in $\mathrm{CHB}$ patients, and effective antiviral therapy increased the vitamin $\mathrm{D}$ level (Hoan et al., 2018).

Bile acid synthesis from cholesterol in hepatocytes is essential for the digestion and absorption of lipids. $\mathrm{Na}^{+} /$taurocholate cotransporter (NTCP/SLC10A1), a sodium-dependent transporter responsible for the basolateral uptake of taurocholate, was found as an entry receptor for HBV (Yan et al., 2012). HBV entry would interfere with the normal function of NTCP for bile acid uptake from portal blood into hepatocytes (Eller et al., 2018). In HBV-infected human liver chimeric mice and liver biopsies of $\mathrm{CHB}$ patients, multiple changes in bile acid metabolism-related genes have been found, especially significantly upregulated expression of hCYP7A1 (Oehler et al., 2014).

\section{THE CONTRIBUTION OF HBX PROTEIN TO CHANGES IN HEPATIC LIPID METABOLISM}

Among the seven $\mathrm{HBV}$ proteins, $\mathrm{HBx}$ is an essential viral regulatory protein and has been demonstrated to interact with various proteins located in the cytoplasm, nucleus, and mitochondria (Ma et al., 2011; Xie et al., 2014; Slagle and Bouchard, 2018). Therefore, the molecular mechanisms underlying lipid metabolism changes resulting from $\mathrm{HBV}$ infection have been mainly focused on the HBx protein. Several studies revealed that $\mathrm{HBx}$ protein overexpression upregulated gene expression and transcriptional activation of $\operatorname{LXR} \alpha / \beta$, SREBP1, C/EBP $\alpha$, and PPAR $\gamma$, which contributed to hepatic lipid synthesis ( $\mathrm{Na}$ et al., 2009; Shieh et al., 2010; Yoon et al., 2011; You et al., 2013; Cui et al., 2014a,b; Wu et al., 2016; Xu et al., 2016; Bai et al., 2017; Wang et al., 2018). In addition to the direct regulation of metabolism-related proteins, HBx was reported to regulate the miRNAs expression, such as miR-384 or miR-205, which subsequently regulated downstream proteins and lipid metabolism (Cui et al., 2014a; Bai et al., 2017). Besides, Wu et al. (2016) showed that $\mathrm{HBx}$ also increased intracellular trafficking of fatty acid by inducing the expression of fatty acid-binding protein 1 (FABP1). Furthermore, some evidence suggested that HBx overexpression 
increased cholesterol level in hepatocytes (Cui et al., 2014b; Wang et al., 2018).

\section{THE EFFECT OF HBV ON APOLIPOPROTEIN METABOLISM IN HEPATOCYTES}

Lipids, including TG, PLs, and cholesterol, are combined with apolipoprotein for their transport and metabolism. Hepatocytes are the major sites of apolipoprotein synthesis and lipoprotein assembly, secretion, uptake, and catabolism. Some clinical studies in $\mathrm{HBV}$-infected population have found significantly decreased levels of plasma ApoA1 (Jiang et al., 2014; Wang Y. et al., 2016; Cui et al., 2019), ApoA5 (Zhu et al., 2016; Cui et al., 2019), ApoB (Wang et al., 2011; Cui et al., 2019), and ApoC3 (Zhu et al., 2017; Cui et al., 2019), whereas dramatically increased level of serum ApoM or ApoE (Gu et al., 2011; Shen et al., 2016). These results from clinical studies were consistent with observations from several experimental studies. ApoA1 promoted cholesterol transfer from peripheral tissues to the liver and increased

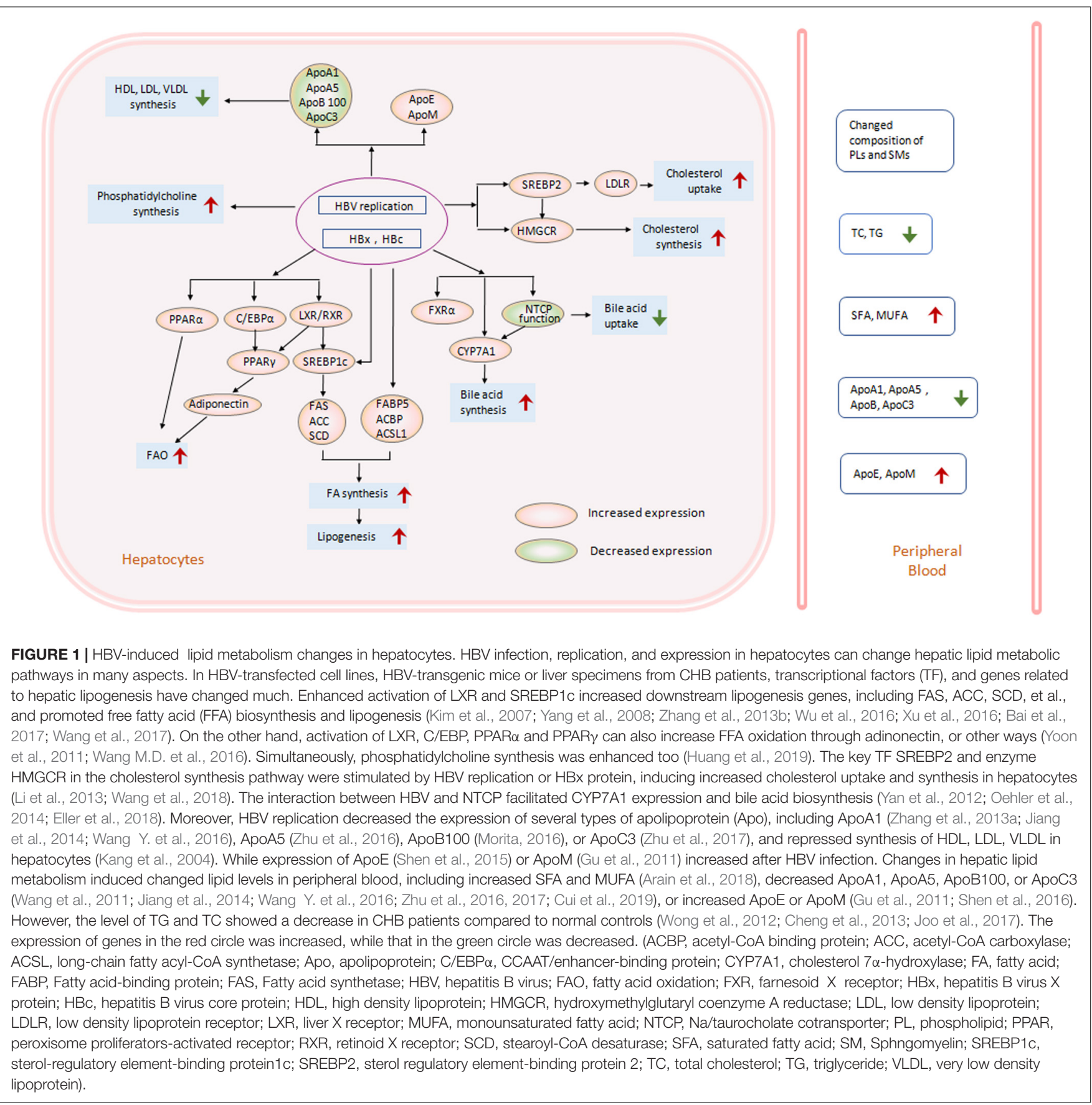


cholesterol metabolism (Chistiakov et al., 2016). In the HepG2.2.15 cell line, HBV upregulated DNA methyltransferase activity to hypermethylate the ApoA1 promoter, thereby inhibited ApoA1 mRNA and protein expression (Jiang et al., 2014; Wang Y. et al., 2016). Besides, the lipid-binding ability of ApoA1 was impaired by its interaction with $\mathrm{HBx}$ (Zhang et al., 2013a), and $\mathrm{HBc}$ protein inhibited the activity of the ApoA5 gene promoter and reduced its expression (Zhu et al., 2016). ApoB100 participated in the transfer of cholesterol to peripheral tissues, which was opposite to the function of ApoA1 (Morita, 2016). Kang et al. (2004) showed that HBx protein overexpression in hepatocytes decreased $A$ poB secretion, increased the intracellular levels of ApoB, TG, and cholesterol, and interfered with VLDL/LDL assembly or secretion. ApoC3 acted as an inhibitor of lipoprotein lipase (LPL), which was a crucial enzyme in TG lipoprotein catabolism (Larsson et al., 2017). A study (Zhu et al., 2017) showed that HBV inhibited the synthesis and secretion of ApoC3. Therefore, during chronic HBV infection, a decrease in ApoC3 expression would increase LPL activity, decrease VLDL synthesis and secretion, and increase TG decomposition.

ApoE acted as a ligand of LDLR or heparan sulfate proteoglycan (HSPG) and played a central role in the transport, metabolism, and homeostasis of cholesterol and other lipids (Getz and Reardon, 2018). HBV infection led to an increase in ApoE expression (Shen et al., 2015), and ApoE promoted HBV infection and production (Qiao and Luo, 2019). ApoM was expressed only in hepatocytes and renal tubular cells, and it promoted HDL ( $\beta$-HDL) formation and increased cholesterol efflux from foam cells (Ren et al., 2015). Overexpression of ApoM showed to inhibit HBV replication in HepG2 cells ( $\mathrm{Gu}$ et al., 2011). Also, the myristoylated pre-S1-domain of the HBV L-protein strongly interacted with apolipoprotein $\mathrm{H}$, which was involved in activation of lipoprotein lipase, and inhibition of platelet prothrombinase activity (Stefas et al., 2001).

These results indicated that HBV replication had complex effects on lipid metabolic pathways (Figure 1). However, most results were obtained from $\mathrm{HBV}$-expressing mice or cell lines.

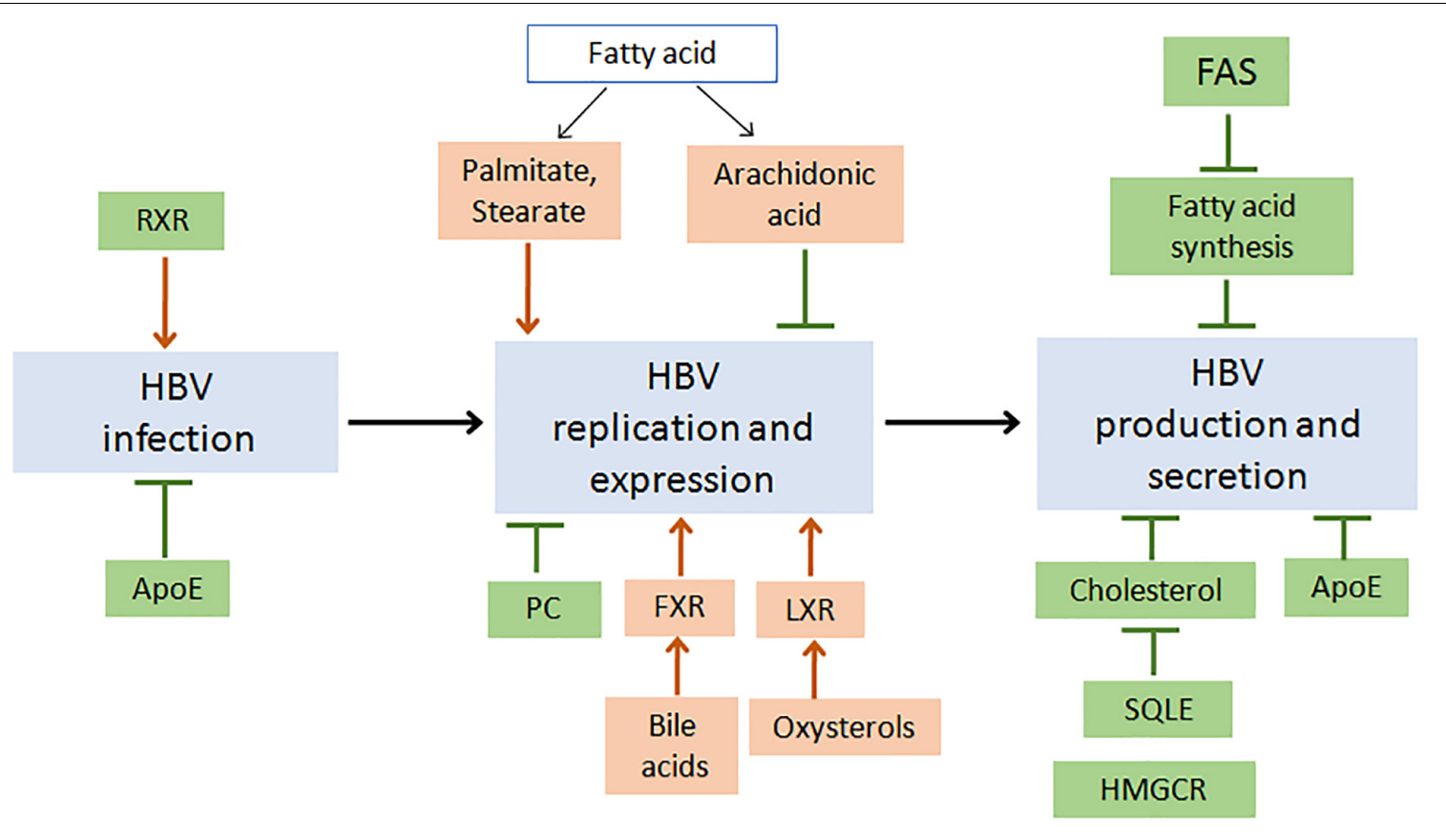

Increased expression

Decreased expression

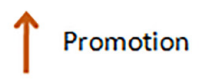

FIGURE 2 | Changes in proteins or metabolites of lipid metabolism pathway affect the life cycle of HBV: potential targets for HBV suppression. Firstly, inhibition of FAS activity decreased fatty acid (FA) synthesis and then suppressed HBV production and secretion (Zhang H. et al., 2013; Cho et al., 2014; Okamura et al., 2016). An increasing level of different FA would induce a different effect on HBV, such as promotion of HBV replication and expression by palmitate or stearate (Cho et al., 2014), while suppression of HBV by arachidonic acid (Song et al., 2018). As cholesterol is the necessary component of HBV particle, inhibition of HMGCR or SQLE decreased cholesterol biosynthesis and suppressed HBV production (Lin et al., 2003; Bremer et al., 2009). Increased HBV replication could be induced through LXR activation by oxysterols or FXR activation by bile acid (Ramière et al., 2008; Kim et al., 2011; Zhao et al., 2018). And inhibition of ApoE decreased HBV infection, production, or secretion (Qiao and Luo, 2019). Besides, decreasing PC synthesis inhibited HBV replication (Tatematsu et al., 2011; Li et al., 2015), and inhibition of RXR increased HBV infection (Reese et al., 2011). Red or green boxes indicated increased or decreased levels of lipid and lipid metabolism-related proteins, respectively. (Apo, apolipoprotein; FA, fatty acid; FAS, Fatty acid synthetase; FXR, farnesoid X receptor; HBV, hepatitis B virus; HMGCR, hydroxymethylglutaryl coenzyme A reductase; LXR, liver X receptor; PC, phosphatidylcholine; RXR, retinoid X receptor; SQLE, Squalene monooxygenase). 
Therefore, to reveal the exact mechanisms of effects of HBV on hepatic lipid metabolism, more data from liver samples of $\mathrm{CHB}$ patients are needed.

\section{HEPATIC LIPID METABOLISM AFFECTING THE LIFE CYCLE OF HBV: POTENTIAL TARGETS FOR HBV SUPPRESSION}

As reviewed above, $\mathrm{HBV}$ infection induced a series of changes in the hepatic lipid metabolic pathways. On the other hand, changes in the levels of metabolic products or expression of metabolism-related proteins conversely affected the life cycle of HBV (Figure 2).

Zhang H. et al. (2013) showed that FAS, a key enzyme of fatty acid synthesis, was highly expressed in HBV transgenic mice, and silencing of FAS expression reduced HBV expression. Okamura et al. (2016) further found that FAS inhibitor decreased HBV particles' production but not genomic replication. Cho et al. (2014) also uncovered that fatty acids (including palmitate, stearate, and oleate) increased HBx protein's stability by preventing proteasome-dependent degradation. In addition to fatty acids, PC biosynthesis inhibition suppressed HBV replication and expression (Tatematsu et al., 2011; Li et al., 2015). Yoon et al. (2011) reported that adiponectin, although as a negative regulator of lipogenic genes (Combs and Marliss, 2014; Gamberi et al., 2018), acted directly on core particles to enhance HBV polymerase activity and HBV DNA replication. Moreover, Song et al. (2018) revealed that arachidonic acid (AA), a kind of PUFA, inhibited HBV infection. It might be because FFAs were potential ligands for toll-like receptor 4 (TLR4) and could activate the innate immune response (Mamedova et al., 2013; Han et al., 2018).

Cholesterol was necessary for the $\mathrm{HBV}$ envelope and played a critical role in $\mathrm{HBV}$ infectivity or viral particle secretion (Lin et al., 2003). Cholesterol depletion and cholesterol synthesis inhibitors, such as inhibitor of HMGCR or squalene cyclooxygenase, impaired secretion of either HBV viral or subviral particles in HBV-producing cell lines (Bremer et al., 2009). Moreover, a study found that oxygenated cholesterol derivatives (also named oxysterols, the endogenous agonists of LXR) increased the transcription and replication of $\mathrm{HBV}$ and reduced the anti-HBV effect of IFN (Kim et al., 2011). Interestingly, a recent study showed synthetic LXR agonists inhibited HBV replication and gene expression through CYP7A1 reduction in $\mathrm{HBV}$-infected primary human hepatocytes, but this observation was not found in hepatocellular carcinoma cell line (Zeng et al., 2020). 25-hydroxycholesterol (25-HC) has been identified to block replication and entry of a broad range of viruses, such as VSV, HIV, EBOV, or ZIKA (Liu et al., 2013; Xiao et al., 2020; Zhao et al., 2020). However, there were few reports about the effect of $25-\mathrm{HC}$ on HBV replication by now. Moreover, the combination use of VitD3 and IFN $\alpha$ enhanced the anti-HBV efficacy of IFN $\alpha$ (Farnik et al., 2013; He et al., 2016; Ko et al., 2020).
The effect of bile acid on HBV infection has received increasing attention. Studies showed that high expression of NTCP induced an increase in bile acid transport to hepatocytes, which promoted HCV and HBV infection by bile-acid-mediated repression of some interferon-stimulated genes (Verrier et al., 2016; Eller et al., 2018). Also, elevated intracellular bile acids activated FXR $\alpha$, which activated HBV enhancer 2/core promoter and consequently enhanced HBV replication (Ramière et al., 2008; Zhao et al., 2018). In addition, FXR $\alpha$ silencing in HBVinfected HepaRG cells decreased the pool size and transcriptional activity of viral covalently closed circular (ccc)DNA (Mouzannar et al., 2019). Other TFs or NRs, such as activator protein1 (AP-1), activating transcription factor 2 (ATF2), or cAMPresponse element-binding protein (CREB), were also reported to be involved in the mechanisms underlying the upregulation of $\mathrm{HBV}$ replication by bile acids.

\section{CONCLUSION}

Hepatitis B virus infection induces multiple changes in hepatic lipid metabolism, by increasing both lipid synthesis and lipolysis. These intracellular changes might be helpful to HBV replication through providing both material and energy. These observations also elucidate why HBV infection facilitates lipid synthesis while the risk of hepatic steatosis in $\mathrm{CHB}$ patients does not noticeably increase, and levels of serum TG and TC decrease. Moreover, targeting a certain lipid metabolism pathway would be a potential therapeutic way to chronic hepatitis B. Given that many studies are limited to cells and animal models and evidence is far from conclusive, more well-designed clinical studies are needed to elucidate the mechanism of this interaction and to discover metabolic targets that could suppress HBV replication or improve the anti-HBV effect of IFN or nucleot(s)ide analogs.

\section{AUTHOR CONTRIBUTIONS}

JZ, NL, and YL: conception and literature review. JZ and MC: writing of the original draft. $\mathrm{MC}$ and $\mathrm{PH}$ : review and editing of the manuscript. MC: funding acquisition. $\mathrm{MP}$ and $\mathrm{PH}$ : supervision of the manuscript. All authors have read and agreed to the published version of the manuscript.

\section{FUNDING}

The present study was sponsored by the National Natural Science Foundation of China (81772198), National Science and Technology Major Project of China (2017ZX10202203 and 2018ZX10302206), and Natural Science Foundation of Chongqing, China (cstc2020jcyj- msxmX0389).

\section{SUPPLEMENTARY MATERIAL}

The Supplementary Material for this article can be found online at: https://www.frontiersin.org/articles/10.3389/fmicb.2021. 636897/full\#supplementary-material 


\section{REFERENCES}

Alves-Bezerra, M., and Cohen, D. E. (2017). Triglyceride Metabolism in the Liver. Comprehens. Physiol. 8, 1-8. doi: 10.1002/cphy.c170012

Arain, S. Q., Talpur, F. N., Channa, N. A., Ali, M. S., and Afridi, H. I. (2018). Serum lipids as an indicator for the alteration of liver function in patients with hepatitis B. Lipids Health Dis. 17:36. doi: 10.1186/s12944-018-0683-y

Bai, P. S., Xia, N., Sun, H., and Kong, Y. (2017). Pleiotrophin, a target of miR-384, promotes proliferation, metastasis and lipogenesis in HBV-related hepatocellular carcinoma. J. Cell. Mol. Med. 21, 3023-3043. doi: 10.1111/jcmm. 13213

Bar-Yishay, I., Shaul, Y., and Shlomai, A. (2011). Hepatocyte metabolic signalling pathways and regulation of hepatitis B virus expression. Liver Int. 31, 282-290. doi: $10.1111 / j .1478-3231.2010 .02423 . x$

Bremer, C. M., Bung, C., Kott, N., Hardt, M., and Glebe, D. (2009). Hepatitis B virus infection is dependent on cholesterol in the viral envelope. Cell. Microbiol. 11, 249-260. doi: 10.1111/j.1462-5822.2008.01250.x

Charatcharoenwitthaya, P., Pongpaibul, A., Kaosombatwattana, U., Bhanthumkomol, P., Bandidniyamanon, W., Pausawasdi, N., et al. (2017). The prevalence of steatohepatitis in chronic hepatitis B patients and its impact on disease severity and treatment response. Liver Int. 37, 542-551. doi: 10.1111/liv.13271

Chen, X. L., Han, Y. D., and Wang, H. (2018). Relations of hepatic steatosis with liver functions, inflammations, glucolipid metabolism in chronic hepatitis B patients. Eur. Rev. Med. Pharmacol. Sci. 22, 5640-5646. doi: 10.26355/eurrev_ 201809_15830

Cheng, Y. L., Wang, Y. J., Kao, W. Y., Chen, P. H., Huo, T. I., Huang, Y. H., et al. (2013). Inverse association between hepatitis B virus infection and fatty liver disease: a large-scale study in populations seeking for check-up. PLoS One 8:e72049. doi: 10.1371/journal.pone.0072049

Chistiakov, D. A., Orekhov, A. N., and Bobryshev, Y. V. (2016). ApoA1 and ApoA1specific self-antibodies in cardiovascular disease. Lab. Investig. J. Technic. Methods Pathol. 96, 708-718. doi: 10.1038/labinvest.2016.56

Cho, H. K., Kim, S. Y., Yoo, S. K., Choi, Y. H., and Cheong, J. (2014). Fatty acids increase hepatitis $B$ virus $X$ protein stabilization and $\mathrm{HBx}$-induced inflammatory gene expression. FEBS J. 281, 2228-2239. doi: 10.1111/febs.12776

Combs, T. P., and Marliss, E. B. (2014). Adiponectin signaling in the liver. Rev. Endocr. Metab. Disord. 15, 137-147. doi: 10.1007/s11154-013-9280-6

Cui, M., Wang, Y., Sun, B., Xiao, Z., Ye, L., and Zhang, X. (2014a). MiR-205 modulates abnormal lipid metabolism of hepatoma cells via targeting acyl-CoA synthetase long-chain family member 1 (ACSL1) mRNA. Biochem. Biophys. Res. Commun. 444, 270-275. doi: 10.1016/j.bbrc.2014.01.051

Cui, M., Xiao, Z., Sun, B., Wang, Y., Zheng, M., Ye, L., et al. (2014b). Involvement of cholesterol in hepatitis B virus X protein-induced abnormal lipid metabolism of hepatoma cells via up-regulating miR-205-targeted ACSL4. Biochem. Biophys. Res. Commun. 445, 651-655. doi: 10.1016/j.bbrc.2014.02.068

Cui, Y., Cui, X. D., Xu, M., Fang, M., and Cai, M. J. (2019). Serum apolipoprotein C3 levels are negatively associated with hepatitis B virus DNA in HBeAgnegative chronic hepatitis B patients. Lipids Health Dis. 18:138. doi: 10.1186/ s12944-019-1084-6

Dittharot, K., Jittorntam, P., Wilairat, P., and Sobhonslidsuk, A. (2018). Urinary Metabolomic Profiling in Chronic Hepatitis B Viral Infection Using Gas Chromatography/Mass Spectrometry. Asian Pac. J. Cancer Prev. 19, 741-748. doi: 10.22034/apjcp.2018.19.3.741

Eller, C., Heydmann, L., Colpitts, C. C., Verrier, E. R., Schuster, C., and Baumert, T. F. (2018). The functional role of sodium taurocholate cotransporting polypeptide NTCP in the life cycle of hepatitis B, C and D viruses. Cell. Mol. Life Sci. CMLS 75, 3895-3905. doi: 10.1007/s00018-018-2892-y

Enomoto, H., Aizawa, N., Nishikawa, H., Ikeda, N., Sakai, Y., Takata, R., et al. (2016). Relationship Between Hepatic Steatosis and the Elevation of Aminotransferases in HBV-Infected Patients With HBe-Antigen Negativity and a Low Viral Load. Medicine 95:e3565. doi: 10.1097/md.0000000000003565

Fang, H., and Judd, R. L. (2018). Adiponectin Regulation and Function. Comprehens. Physiol. 8, 1031-1063. doi: 10.1002/cphy.c170046

Farnik, H., Bojunga, J., Berger, A., Allwinn, R., Waidmann, O., Kronenberger, B., et al. (2013). Low vitamin D serum concentration is associated with high levels of hepatitis B virus replication in chronically infected patients. Hepatology 58, 1270-1276. doi: 10.1002/hep.26488
Gamberi, T., Magherini, F., Modesti, A., and Fiaschi, T. (2018). Adiponectin Signaling Pathways in Liver Diseases. Biomedicines 6:6020052. doi: 10.3390/ biomedicines 6020052

Getz, G. S., and Reardon, C. A. (2018). Apoprotein E and Reverse Cholesterol Transport. Int. J. Mol. Sci. 19:19113479. doi: 10.3390/ijms19113479

Gu, J. G., Zhu, C. L., Cheng, D. Z., Xie, Y., Liu, F., and Zhou, X. (2011). Enchanced levels of apolipoprotein M during HBV infection feedback suppresses HBV replication. Lipids Health Dis. 10:154. doi: 10.1186/1476-511x-10-154

Han, L.-P., Sun, B., Li, C.-J., Xie, Y., and Chen, L.-M. (2018). Effect of celastrol on toll-like receptor 4-mediated inflammatory response in free fatty acid-induced HepG2 cells. Int. J. Mol. Med. 42, 2053-2061. doi: 10.3892/ijmm.2018.3775

He, L.-J., Zhang, H.-P., Li, H.-J., Wang, J., and Chang, D.-D. (2016). Effect of Serum Vitamin D Levels on Cellular Immunity and Antiviral Effects in Chronic Hepatitis B Patients. Clin. Lab. 62, 1933-1939. doi: 10.7754/Clin.Lab.2016. 160210

Hoan, N. X., Tong, H. V., Song, L. H., Meyer, C. G., and Velavan, T. P. (2018). Vitamin D deficiency and hepatitis viruses-associated liver diseases: A literature review. World J. Gastroenterol. 24, 445-460. doi: 10.3748/wjg.v24.i4.445

Huang, Q., Lei, H., Ding, L., and Wang, Y. (2019). Stimulated phospholipid synthesis is key for hepatitis B virus replications. Sci. Rep. 9:12989. doi: 10.1038/ s41598-019-49367-8

Hui, R. W. H., Seto, W. K., Cheung, K. S., Mak, L. Y., Liu, K. S. H., Fung, J., et al. (2018). Inverse relationship between hepatic steatosis and hepatitis B viremia: Results of a large case-control study. J. Viral Hepat. 25, 97-104. doi: $10.1111 /$ jvh. 12766

Jiang, H., Cheng, S.-T., Ren, J.-H., Ren, F., Yu, H.-B., Wang, Q., et al. (2019). SIRT6 Inhibitor, OSS_128167 Restricts Hepatitis B Virus Transcription and Replication Through Targeting Transcription Factor Peroxisome ProliferatorActivated Receptors $\alpha$. Front. Pharmacol. 10:1270. doi: 10.3389/fphar.2019. 01270

Jiang, W., Zheng, L., Yang, Q., Huang, Z., and Wang, X. (2014). Investigation into the effect of hepatitis B virus on apoliprotein A1 expression and its mechanism. Lipids Health Dis. 13:130. doi: 10.1186/1476-511x-13-130

Joo, E. J., Chang, Y., Yeom, J. S., and Ryu, S. (2017). Hepatitis B virus infection and decreased risk of nonalcoholic fatty liver disease: A cohort study. Hepatology 65, 828-835. doi: 10.1002/hep.28917

Kang, S. K., Chung, T. W., Lee, J. Y., Lee, Y. C., Morton, R. E., and Kim, C. H. (2004). The hepatitis B virus X protein inhibits secretion of apolipoprotein B by enhancing the expression of $\mathrm{N}$-acetylglucosaminyltransferase III. J. Biol. Chem. 279, 28106-28112. doi: 10.1074/jbc.M403176200

Kim, H. Y., Cho, H. K., Kim, H. H., and Cheong, J. (2011). Oxygenated derivatives of cholesterol promote hepatitis B virus gene expression through nuclear receptor LXR $\alpha$ activation. Virus Res. 158, 55-61. doi: 10.1016/j.virusres.2011. 03.010

Kim, K. H., Shin, H.-J., Kim, K., Choi, H. M., Rhee, S. H., Moon, H.-B., et al. (2007). Hepatitis B virus $X$ protein induces hepatic steatosis via transcriptional activation of SREBP1 and PPARgamma. Gastroenterology 132, 1955-1967.

Ko, W.-S., Yang, Y.-P., Shen, F.-P., Wu, M.-C., Shih, C.-J., Lu, M.-C., et al. (2020). The Study of Correlation Between Serum Vitamin D Concentrations and HBV DNA Levels and Immune Response in Chronic Hepatitis Patients. Nutrients 12:12041114. doi: 10.3390/nu12041114

Lamontagne, R. J., Casciano, J. C., and Bouchard, M. J. (2018). A broad investigation of the HBV-mediated changes to primary hepatocyte physiology reveals HBV significantly alters metabolic pathways. Metab. Clin. Exp. 83, 50-59. doi: 10.1016/j.metabol.2018.01.007

Larsson, M., Allan, C. M., Jung, R. S., Heizer, P. J., Beigneux, A. P., Young, S. G., et al. (2017). Apolipoprotein C-III inhibits triglyceride hydrolysis by GPIHBP1-bound LPL. J. Lipid Res. 58, 1893-1902. doi: 10.1194/jlr.M078220

Li, H., Zhu, W., Zhang, L., Lei, H., Wu, X., Guo, L., et al. (2015). The metabolic responses to hepatitis B virus infection shed new light on pathogenesis and targets for treatment. Sci. Rep. 5:8421. doi: 10.1038/srep08421

Li, Y. J., Zhu, P., Liang, Y., Yin, W. G., and Xiao, J. H. (2013). Hepatitis B virus induces expression of cholesterol metabolism-related genes via TLR2 in HepG2 cells. World J. Gastroenterol. 19, 2262-2269. doi: 10.3748/wjg.v19.i14.2262

Lin, C.-W., Huang, X.-L., Liu, H.-L., and Wang, Y. (2015). Interactions of Hepatitis B Virus Infection with Nonalcoholic Fatty Liver Disease: Possible Mechanisms and Clinical Impact. Digest. Dis. Sci. 60, 3513-3524. doi: 10.1007/s10620-0153772-z 
Lin, Y. L., Shiao, M. S., Mettling, C., and Chou, C. K. (2003). Cholesterol requirement of hepatitis B surface antigen (HBsAg) secretion. Virology 314, 253-260. doi: 10.1016/s0042-6822(03)00403-3

Liu, S.-Y., Aliyari, R., Chikere, K., Li, G., Marsden, M. D., Smith, J. K., et al. (2013). Interferon-inducible cholesterol-25-hydroxylase broadly inhibits viral entry by production of 25-hydroxycholesterol. Immunity 38, 92-105. doi: 10. 1016/j.immuni.2012.11.005

Ma, J., Sun, T., Park, S., Shen, G., and Liu, J. (2011). The role of hepatitis B virus $\mathrm{X}$ protein is related to its differential intracellular localization. Acta Biochim. Biophys. Sinica 43, 583-588. doi: 10.1093/abbs/gmr048

Machado, M. V., Oliveira, A. G., and Cortez-Pinto, H. (2011). Hepatic steatosis in hepatitis B virus infected patients: meta-analysis of risk factors and comparison with hepatitis C infected patients. J. Gastroenterol. Hepatol. 26, 1361-1367. doi: 10.1111/j.1440-1746.2011.06801.x

Mamedova, L. K., Yuan, K., Laudick, A. N., Fleming, S. D., Mashek, D. G., and Bradford, B. J. (2013). Toll-like receptor 4 signaling is required for induction of gluconeogenic gene expression by palmitate in human hepatic carcinoma cells. J. Nutrit. Biochem. 24, 1499-1507. doi: 10.1016/j.jnutbio.2012.12.009

Megahed, F. A. K., Zhou, X., and Sun, P. (2020). The Interactions between HBV and the Innate Immunity of Hepatocytes. Viruses 12:12030285. doi: 10.3390/ v12030285

Morita, S.-Y. (2016). Metabolism and Modification of Apolipoprotein B-Containing Lipoproteins Involved in Dyslipidemia and Atherosclerosis. Biol. Pharmaceut. Bull. 39:716. doi: 10.1248/bpb.b15-00716

Mouzannar, K., Fusil, F., Lacombe, B., Ollivier, A., Ménard, C., Lotteau, V., et al. (2019). Farnesoid X receptor- $\alpha$ is a proviral host factor for hepatitis B virus that is inhibited by ligands in vitro and in vivo. FASEB J. 33, 2472-2483. doi: 10.1096/fj.201801181R

Na, T.-Y., Shin, Y. K., Roh, K. J., Kang, S.-A., Hong, I., Oh, S. J., et al. (2009). Liver $\mathrm{X}$ receptor mediates hepatitis $\mathrm{B}$ virus $\mathrm{X}$ protein-induced lipogenesis in hepatitis B virus-associated hepatocellular carcinoma. Hepatology 49, 1122-1131. doi: 10.1002/hep.22740

Oehler, N., Volz, T., Bhadra, O. D., Kah, J., Allweiss, L., Giersch, K., et al. (2014). Binding of hepatitis B virus to its cellular receptor alters the expression profile of genes of bile acid metabolism. Hepatology 60, 1483-1493. doi: 10.1002/hep. 27159

Okamura, H., Nio, Y., Akahori, Y., Kim, S., Watashi, K., Wakita, T., et al. (2016). Fatty acid biosynthesis is involved in the production of hepatitis B virus particles. Biochem. Biophys. Res. Commun. 475, 87-92. doi: 10.1016/j.bbrc.2016. 05.043

Peng, D., Han, Y., Ding, H., and Wei, L. (2008). Hepatic steatosis in chronic hepatitis $\mathrm{B}$ patients is associated with metabolic factors more than viral factors. J. Gastroenterol. Hepatol. 23(7 Pt 1), 1082-1088. doi: 10.1111/j.1440-1746.2008. 05478.x

Prabhu, A. V., Luu, W., Li, D., Sharpe, L. J., and Brown, A. J. (2016). DHCR7: A vital enzyme switch between cholesterol and vitamin D production. Prog. Lipid Res. 64, 138-151. doi: 10.1016/j.plipres.2016.09.003

Qiao, L., and Luo, G. G. (2019). Human apolipoprotein E promotes hepatitis B virus infection and production. PLoS Pathog. 15:e1007874. doi: 10.1371/journal. ppat.1007874

Qu, F., Zheng, S. J., Liu, S., Wu, C. S., Duan, Z. P., and Zhang, J. L. (2014). Serum sphingolipids reflect the severity of chronic HBV infection and predict the mortality of HBV-acute-on-chronic liver failure. PLoS One 9:e104988. doi: 10.1371/journal.pone. 0104988

Ramière, C., Scholtès, C., Diaz, O., Icard, V., Perrin-Cocon, L., Trabaud, M.-A., et al. (2008). Transactivation of the hepatitis B virus core promoter by the nuclear receptor FXRalpha. J. Virol. 82, 10832-10840. doi: 10.1128/JVI.008 83-08

Reese, V., Ondracek, C., Rushing, C., Li, L., Oropeza, C. E., and McLachlan, A. (2011). Multiple nuclear receptors may regulate hepatitis B virus biosynthesis during development. Int. J. Biochem. Cell Biol. 43, 230-237. doi: 10.1016/j. biocel.2009.11.016

Ren, K., Tang, Z.-L., Jiang, Y., Tan, Y.-M., and Yi, G.-H. (2015). Apolipoprotein M. Clin. Chim. Acta Int. J. Clin. Chem. 446, 21-29. doi: 10.1016/j.cca.2015.03.038

Rodgers, M. A., Saghatelian, A., and Yang, P. L. (2009). Identification of an overabundant cholesterol precursor in hepatitis B virus replicating cells by untargeted lipid metabolite profiling. J. Am. Chem. Soc. 131, 5030-5031. doi: $10.1021 /$ ja 809949 r
Schoeman, J. C., Hou, J., Harms, A. C., Vreeken, R. J., Berger, R., Hankemeier, T., et al. (2016). Metabolic characterization of the natural progression of chronic hepatitis B. Genome Med. 8:64. doi: 10.1186/s13073-016-0318-8

Shen, T., Wu, W. M., Du, W. H., Wang, L., He, G., Tan, L., et al. (2016). Positive association between serum apolipoprotein $\mathrm{M}$ levels and hepatitis B virus DNA load in HBeAg-negative chronic hepatitis B. Lipids Health Dis. 15:210. doi: 10.1186/s12944-016-0384-3

Shen, Y., Li, M., Ye, X., and Bi, Q. (2015). Association of apolipoprotein E with the progression of hepatitis B virus-related liver disease. Int. J. Clin. Exp. Pathol. 8, 14749-14756.

Shi, J. P., Fan, J. G., Wu, R., Gao, X. Q., Zhang, L., Wang, H., et al. (2008). Prevalence and risk factors of hepatic steatosis and its impact on liver injury in Chinese patients with chronic hepatitis B infection. J. Gastroenterol. Hepatol. 23, 1419-1425. doi: 10.1111/j.1440-1746.2008.05531.x

Shi, Y.-X., Huang, C.-J., and Yang, Z.-G. (2016). Impact of hepatitis B virus infection on hepatic metabolic signaling pathway. World J. Gastroenterol. 22, 8161-8167. doi: 10.3748/wjg.v22.i36.8161

Shieh, Y.-S., Chang, Y.-S., Hong, J.-R., Chen, L.-J., Jou, L.-K., Hsu, C.-C., et al. (2010). Increase of hepatic fat accumulation by liver specific expression of Hepatitis B virus X protein in zebrafish. Biochim. Biophys. Acta 1801, 721-730. doi: 10.1016/j.bbalip.2010.04.008

Slagle, B. L., and Bouchard, M. J. (2018). Role of HBx in hepatitis B virus persistence and its therapeutic implications. Curr. Opin. Virol. 30, 32-38. doi: 10.1016/j. coviro.2018.01.007

Song, M., Sun, Y., Tian, J., He, W., Xu, G., Jing, Z., et al. (2018). Silencing Retinoid $\mathrm{X}$ Receptor Alpha Expression Enhances Early-Stage Hepatitis B Virus Infection In Cell Cultures. J. Virol. 92:17. doi: 10.1128/jvi.01771-17

Stefas, I., Rucheton, M., D’Angeac, A. D., Morel-Baccard, C., Seigneurin, J. M., Zarski, J. P., et al. (2001). Hepatitis B virus Dane particles bind to human plasma apolipoprotein H. Hepatology 33, 207-217. doi: 10.1053/jhep.2001.2 0531

Suliman, I., Abdelgelil, N., Kassamali, F., and Hassanein, T. I. (2019). The Effects of Hepatic Steatosis on the Natural History of HBV Infection. Clin. Liver Dis. 23, 433-450. doi: 10.1016/j.cld.2019.05.001

Tatematsu, K., Tanaka, Y., Sugiyama, M., Sudoh, M., and Mizokami, M. (2011). Host sphingolipid biosynthesis is a promising therapeutic target for the inhibition of hepatitis B virus replication. J. Med. Virol. 83, 587-593. doi: 10. 1002/jmv. 21970

Verrier, E. R., Colpitts, C. C., Bach, C., Heydmann, L., Zona, L., Xiao, F., et al. (2016). Solute Carrier NTCP Regulates Innate Antiviral Immune Responses Targeting Hepatitis C Virus Infection of Hepatocytes. Cell Rep. 17, 1357-1368. doi: 10.1016/j.celrep.2016.09.084

Wagner, M., Zollner, G., and Trauner, M. (2011). Nuclear receptors in liver disease. Hepatology 53, 1023-1034. doi: 10.1002/hep.24148

Wang, B., Li, W., Fang, H., and Zhou, H. (2019). Hepatitis B virus infection is not associated with fatty liver disease: Evidence from a cohort study and functional analysis. Mol. Med. Rep. 19, 320-326. doi: 10.3892/mmr.2018.9619

Wang, C.-C., Tseng, T.-C., and Kao, J.-H. (2015). Hepatitis B virus infection and metabolic syndrome: fact or fiction? J. Gastroenterol. Hepatol. 30, 14-20. doi: 10.1111/jgh. 12700

Wang, Y., Viscarra, J., Kim, S.-J., and Sul, H. S. (2015 ). Transcriptional regulation of hepatic lipogenesis. Nat. Rev. Mol. Cell Biol. 16, 678-689. doi: 10.1038/nrm 4074

Wang, F. B., Zhu, C. L., Liu, X., and Gao, G. S. (2011). HBV inhibits apoB production via the suppression of MTP expression. Lipids Health Dis. 10:207. doi: 10.1186/1476-511x-10-207

Wang, M. M., Wang, G. S., Shen, F., Chen, G. Y., Pan, Q., and Fan, J. G. (2014). Hepatic steatosis is highly prevalent in hepatitis B patients and negatively associated with virological factors. Dig. Dis. Sci. 59, 2571-2579. doi: 10.1007/ s10620-014-3180-9

Wang, M.-D., Wu, H., Huang, S., Zhang, H.-L., Qin, C.-J., Zhao, L.-H., et al. (2016). HBx regulates fatty acid oxidation to promote hepatocellular carcinoma survival during metabolic stress. Oncotarget 7, 6711-6726. doi: 10.18632/ oncotarget.6817

Wang, S.-H., Yeh, S.-H., Lin, W.-H., Yeh, K.-H., Yuan, Q., Xia, N.-S., et al. (2012). Estrogen receptor $\alpha$ represses transcription of HBV genes via interaction with hepatocyte nuclear factor $4 \alpha$. Gastroenterology 142:45. doi: 10.1053/j.gastro. 2011.12.045 
Wang, Y., Cai, X., Zhang, S., Cui, M., Liu, F., Sun, B., et al. (2017). HBXIP upregulates ACSL1 through activating transcriptional factor $\mathrm{Sp} 1$ in breast cancer. Biochem. Biophys. Res. Commun. 484, 565-571. doi: 10.1016/j.bbrc.2017.01.126

Wang, Y., Hao, J., Liu, X., Wang, H., Zeng, X., Yang, J., et al. (2016). The mechanism of apoliprotein A1 down-regulated by Hepatitis B virus. Lipids Health Dis. 15:64. doi: 10.1186/s12944-016-0232-5

Wang, Y., Wu, T., Hu, D., Weng, X., Wang, X., Chen, P. J., et al. (2018). Intracellular hepatitis $\mathrm{B}$ virus increases hepatic cholesterol deposition in alcoholic fatty liver via hepatitis B core protein. J. Lipid Res. 59, 58-68. doi: 10.1194/jlr.M079533

Wong, V. W., Wong, G. L., Chu, W. C., Chim, A. M., Ong, A., Yeung, D. K., et al. (2012). Hepatitis B virus infection and fatty liver in the general population. J. Hepatol. 56, 533-540. doi: 10.1016/j.jhep.2011.09.013

Wu, Y.-L., Peng, X.-E., Zhu, Y.-B., Yan, X.-L., Chen, W.-N., and Lin, X. (2016). Hepatitis B Virus X Protein Induces Hepatic Steatosis by Enhancing the Expression of Liver Fatty Acid Binding Protein. J. Virol. 90, 1729-1740. doi: 10.1128/JVI.02604- 15

Xiao, J., Li, W., Zheng, X., Qi, L., Wang, H., Zhang, C., et al. (2020). Targeting 7-Dehydrocholesterol Reductase Integrates Cholesterol Metabolism and IRF3 Activation to Eliminate Infection. Immunity 52:15. doi: 10.1016/j.immuni.2019. 11.015

Xie, N., Chen, X., Zhang, T., Liu, B., and Huang, C. (2014). Using proteomics to identify the HBx interactome in hepatitis B virus: how can this inform the clinic? Expert Rev. Proteomics 11, 59-74. doi: 10.1586/14789450.2014.861745

Xu, Z., Zhai, L., Yi, T., Gao, H., Fan, F., Li, Y., et al. (2016). Hepatitis B virus $\mathrm{X}$ induces inflammation and cancer in mice liver through dysregulation of cytoskeletal remodeling and lipid metabolism. Oncotarget 7, 70559-70574. doi: 10.18632/oncotarget.12372

Yan, H., Zhong, G., Xu, G., He, W., Jing, Z., Gao, Z., et al. (2012). Sodium taurocholate cotransporting polypeptide is a functional receptor for human hepatitis B and D virus. eLife 1:e00049. doi: 10.7554/eLife.00049

Yang, F., Yan, S., He, Y., Wang, F., Song, S., Guo, Y., et al. (2008). Expression of hepatitis B virus proteins in transgenic mice alters lipid metabolism and induces oxidative stress in the liver. J. Hepatol. 48, 12-19. doi: 10.1016/j.jhep.2007.06. 021

Yang, L., Yang, X., Kong, X., Cao, Z., Zhang, Y., Hu, Y., et al. (2016). Covariation Analysis of Serumal and Urinary Metabolites Suggests Aberrant Glycine and Fatty Acid Metabolism in Chronic Hepatitis B. PLoS One 11:e0156166. doi: 10.1371/journal.pone.0156166

Yasumoto, J., Kasai, H., Yoshimura, K., Otoguro, T., Watashi, K., Wakita, T., et al. (2017). Hepatitis B virus prevents excessive viral production via reduction of cell death-inducing DFF45-like effectors. J. Gen. Virol. 98, 1762-1773. doi: 10.1099/jgv.0.000813

Yoon, S., Jung, J., Kim, T., Park, S., Chwae, Y.-J., Shin, H.-J., et al. (2011). Adiponectin, a downstream target gene of peroxisome proliferator-activated receptor $\gamma$, controls hepatitis B virus replication. Virology 409, 290-298. doi: 10.1016/j.virol.2010.10.024

You, X., Liu, F., Zhang, T., Li, Y., Ye, L., and Zhang, X. (2013). Hepatitis B virus $\mathrm{X}$ protein upregulates oncogene Rab18 to result in the dysregulation of lipogenesis and proliferation of hepatoma cells. Carcinogenesis 34, 1644-1652. doi: $10.1093 /$ carcin/bgt089
Zeng, J., Wu, D., Hu, H., Young, J. A. T., Yan, Z., and Gao, L. (2020). Activation of the liver $\mathrm{X}$ receptor pathway inhibits $\mathrm{HBV}$ replication in primary human hepatocytes. Hepatology Preprint. doi: 10.1002/hep.31217

Zhang, H., Li, H., Yang, Y., Li, S., Ren, H., Zhang, D., et al. (2013). Differential regulation of host genes including hepatic fatty acid synthase in HBV-transgenic mice. J. Proteome Res. 12, 2967-2979. doi: 10.1021/pr400 $247 \mathrm{f}$

Zhang, T., Xie, N., He, W., Liu, R., Lei, Y., Chen, Y., et al. (2013a). An integrated proteomics and bioinformatics analyses of hepatitis $\mathrm{B}$ virus $\mathrm{X}$ interacting proteins and identification of a novel interactor apoA-I. J. Proteomics 84, 92-105. doi: 10.1016/j.jprot.2013.03.028

Zhang, T., Zhang, J., Cui, M., Liu, F., You, X., Du, Y., et al. (2013b). Hepatitis $B$ virus $X$ protein inhibits tumor suppressor miR-205 through inducing hypermethylation of miR-205 promoter to enhance carcinogenesis. Neoplasia $15,1282-1291$.

Zhao, J., Chen, J., Li, M., Chen, M., and Sun, C. (2020). Multifaceted Functions of $\mathrm{CH} 25 \mathrm{H}$ and $25 \mathrm{HC}$ to Modulate the Lipid Metabolism, Immune Responses, and Broadly Antiviral Activities. Viruses 12:12070727. doi: 10.3390/v12070727

Zhao, K., Liu, S., Chen, Y., Yao, Y., Zhou, M., Yuan, Y., et al. (2018). Upregulation of HBV transcription by sodium taurocholate cotransporting polypeptide at the postentry step is inhibited by the entry inhibitor Myrcludex B. Emerg. Microbes Infect. 7:186. doi: 10.1038/s41426-018-0189-8

Zheng, R. D., Xu, C. R., Jiang, L., Dou, A. X., Zhou, K., and Lu, L. G. (2010). Predictors of hepatic steatosis in HBeAg-negative chronic hepatitis B patients and their diagnostic values in hepatic fibrosis. Int. J. Med. Sci. 7, 272-277. doi: 10.7150/ijms.7.272

Zhong, G. C., Wu, Y. L., Hao, F. B., Rao, X. W., Yuan, X. W., Zhao, Y., et al. (2018). Current but not past hepatitis B virus infection is associated with a decreased risk of nonalcoholic fatty liver disease in the Chinese population: A case-control study with propensity score analysis. J. Viral Hepat. 25, 842-852. doi: $10.1111 /$ jvh. 12878

Zhu, C., Gao, G., Song, H., Xu, F., Wu, K., and Liu, X. (2016). Hepatitis B virus inhibits apolipoprotein A5 expression through its core gene. Lipids Health Dis. 15:178. doi: 10.1186/s12944-016-0340-2

Zhu, C., Zhu, H., Song, H., Xu, L., Li, L., Liu, F., et al. (2017). Hepatitis B virus inhibits the in vivo and in vitro synthesis and secretion of apolipoprotein C3. Lipids Health Dis. 16:213. doi: 10.1186/s12944-017-0607-2

Zhu, L., Jiang, J., Zhai, X., Baecker, A., Peng, H., Qian, J., et al. (2019). Hepatitis B virus infection and risk of non-alcoholic fatty liver disease: A population-based cohort study. Liver Int. 39, 70-80. doi: 10.1111/liv.13933

Conflict of Interest: The authors declare that the research was conducted in the absence of any commercial or financial relationships that could be construed as a potential conflict of interest.

Copyright (C) 2021 Zhang, Ling, Lei, Peng, Hu and Chen. This is an open-access article distributed under the terms of the Creative Commons Attribution License (CC BY). The use, distribution or reproduction in other forums is permitted, provided the original author(s) and the copyright owner(s) are credited and that the original publication in this journal is cited, in accordance with accepted academic practice. No use, distribution or reproduction is permitted which does not comply with these terms. 